\title{
Analisis penurunan keterlambatan pengiriman di PT. Naratama Sayagi Indonesia menggunakan metode sequencing
}

\author{
Ratna Senjaya $^{1)^{*}}$, Sutrisno $^{2)}$ \\ ${ }^{12}$ Universitas Singaperbangsa Karawang, Jalan H. S. Ronggowaluyo, Telukjambe, Karawang, Indonesia. \\ 1810631140049@student.unsika.ac.id*; tris.sutrisno@ft.unsika.ac.id
}

\begin{abstract}
ABSTRAK
PT. Naratama Sayagi Indonesia bergerak di bidang jasa machining bubut dan CNC milling dimana perusahaan menggunakan sistem make to order dengan mendahulukan pesanan yang pertama kali masuk, maka ketepatan waktu penyelesaian dan kualitas produksi merupakan hal yang sangat penting. Tujuan penelitian adalah menurunkan keterlambatan pengiriman yang disebabkan proses produksi sehingga perlu adanya penjadwalan dalam proses produksi agar dapat berjalan lancar. Pada penelitian ini menggunakan metode FCFS (First Come First Served), SPT (Short Processing Time), LPT (Long Processing Time), dan EDD (Earliest Due Date). Selanjutnya membandingkan antar metode yang digunakan dan diperoleh metode SPT merupakan hasil yang paling optimal yaitu waktu penyelesaian rata-rata pada bulan Desember 52 hari, bulan Januari yaitu 59 hari, dan bulan Februari yaitu 84 hari. Memiliki nilai utilitas pada bulan Desember yaitu 19\%, bulan Januari yaitu $12 \%$, dan bulan Februari yaitu $10 \%$. Dengan jumlah pekerjaan rata-rata pada bulan Desember yaitu 5,26 job, bulan Januari yaitu 8,52 job, dan bulan Februari yaitu 9,62 job. Selanjutnya keterlambatan rata-rata pada bulan Desember yaitu 39,2 hari, bulan Januari yaitu 47,5 hari, dan pada bulan Februari yaitu 42,6 hari. Sehingga metode SPT dapat diterapkan pada proses produksi dimana akan membantu perusahaan dalam menurunkan proses pengiriman yang terlambat.
\end{abstract}

Kata kunci: Penjadwalan Produksi, FCFS, SPT, LPT, EDD

\section{ABSTRACT}

PT. Naratama Sayagi Indonesia is engaged in lathe machining and CNC milling services were using a make-toorder system by prioritizing orders according to incoming times, timely completion and quality of production are very important. The purpose of the research is the delay in delivery caused by the production process so it is necessary to have a production schedule so that it can run smoothly. This study using the FCFS (First Come First Served), SPT (Short Processing Time), LPT (Long Processing Time), and EDD (Earliest Due Date) methods. Furthermore, comparing the methods used and the SPT method obtained is the most optimal result, namely the average completion time in December is 52 days, January is 59 days, and February is 84 days. It has a utility value in December which is 19\%, January is 12\%, and February is 10\%. The average number of jobs in December is 5.26 jobs, January is 8.52 jobs, and February is 9.62 jobs. Furthermore, the average delay in December is 39.2 days, January is 47.5 days, and February is 42.6 days. So that the SPT method can be applied to the production process which will help the company in reducing the late delivery process.

Keywords: Production Scheduling, FCFS, SPT, LPT, EDD

diunggah: Oktober 2021, direvisi: Desember 2021, diterima: Desember 2021, dipublikasi: Desember 2021

Copyright (c) 2021 Ratna Senjaya, Sutrisno

This is an open access article under the CC-BY license

\section{PENDAHULUAN}

Setiap perusahaan harus mampu menghadapi persaingan yang ada salah satunya mampu memberikan pelayanan untuk kepuasan pelanggan, dimana suatu perusahaan sering mengalami permasalahan yaitu terjadinya keterlambatan dalam proses pengiriman yang disebabkan oleh proses produksi yang tidak tepat waktu. Mencapai target untuk memperoleh 
barang produksi dengan tepat waktu beserta jumlah yang sudah direncanakan merupakan kegiatan dalam industri manufaktur. Sehingga untuk manghasilkan barang suatu perusahaan perlu merancang proses produksi secara akurat agar lebih efektif dan efisien dalam mencapai tujuan yang telah ditentukan. Demi menjaga kepercayaan konsumen juga perlu untuk memperhatikan kualitas yang dihasilkan selama proses produksi (Ulina \& Bakhtiar, 2019).

Berbagai penelitian sudah dilakukan sebelumnya dimana (Mulya et al., 2020) menerapkan metode Earlist Due Date (EDD), (Subroto et al., 2019) menerapkan metode Earlist Due Date (EDD) dan metode Short Processing Time ( SPT), (Febianti \& Mardiana, 2019) menerapkan metode First Come First Served (FCFS) dan metode Earlist Due Date (EDD) serta masih banyak lagi metode yang digunakan dengan membandingkannya antar metode yang digunakan. Pada penelitian sebelumnya masih menggunakan beberapa metode sehingga pada penelitian kali ini menggunakan penambahan metode dan pada objek yang berbeda, dimana untuk mengetahui metode yang optimal.

PT. Naratama Sayagi Indonesia (NSI) merupakan perusahaan yang begerak dibidang jasa, dimana dalam proses penyelesaian pesanan yang telah ditentukan masih mengalami keterlambatan. Tidak sesuainya proses produksi dapat menyebabkan keterlambatan dimana barang tidak dapat dikirim dengan tepat waktu. Berikut ini tabel 1 merupakan data keterlambatan yang terjadi karena memenuhi permintaan konsumen. Dapat dilihat bahwa dalam memenuhi permintaan konsumen, sering terjadi keterlambatan selama proses berlangsung.

Tabel 1. Data keterlambatan bulan desember-februari

\begin{tabular}{lccc}
\hline \multicolumn{1}{c}{ Item } & Qty & Delivery Req & $\begin{array}{c}\text { Finish } \\
\text { Production }\end{array}$ \\
\hline Stud - Include Material & 14 & 14-Dec-20 & 21-Jan-21 \\
Cond-Finish Mach (Exclude) & 38 & 14-Dec-20 & 27-Jan-21 \\
Elerd - Finish Mach (Exclude) & 4 & 14-Dec-20 & 27-Jan-21 \\
Rod - Finish Mach (Exclude) & 5 & 14-Dec-20 & 09-Feb-21 \\
B - Finish Mach (Exclude) & 12 & 14-Dec-20 & 28-Dec-20 \\
Shld - Finish Mach & 12 & 18-Dec-20 & 11-Jan-21 \\
Plg-Finish Mach Exclude & 15 & 18-Dec-20 & 21-Jan-21 \\
Cvr - Finish Part (Exclude) & 12 & 18-Dec-20 & 26-Jan-21 \\
Supp - Cutting & 1 & 10-Dec-20 & 11-Jan-21 \\
Plt-Include Material & 12 & 01-Apr-21 & 24-Jan-21 \\
Seat - Finish Mach & 29 & 14-Jan-21 & 31-Jan-21 \\
C1020p-1/2h - Cutting & 11 & 20-Jan-21 & 05-Feb-21 \\
Supp - Finish Mach - Exclude Material & 11 & 15-Feb-21 & 02-Mar-21 \\
Bond - Milling As Per Finish Length & 3 & 15-Feb-21 & 27-Feb-21 \\
Hook - Finish Part - Exclude & 6 & 15-Feb-21 & 05-Mar-21 \\
Cyl - Finish Mach & 3 & 23-Feb-21 & 26-Feb-21 \\
Cyl/W - Milling Inside To 19mm & 3 & 25-Feb-21 & 05-Mar-21 \\
Pin - Finish Mach - Exclude & 12 & 25-Feb-21 & 08-Mar-21 \\
Bond - Cutting, Milling From Thik 12 To Finish & 2 & 22-Feb-21 & 25-Feb-21 \\
Drawing & & & \\
\hline
\end{tabular}

Setiap perusahaan memiliki batas waktu yang sudah ditentukan untuk menyelesaikan pesanan dengan tepat waktu. Pesanan yang diselesaikan dalam waktu yang telah dijadwalkan akan memberikan kepuasan kepada konsumen (Supriyanto, 2013).

Pesanan dapat diselesaikan sesuai dengan waktu yang sudah direncanakan, sehingga perlu adanya suatu perencanaan produksi dimana untuk menentukan jadwal kegiatan 
produksi agar suatu kegiatan dapat terkendali sehingga berjalan dengan lancar dan memperoleh target yang sudah ditentukan (Patricia \& Suryono, 2015). Dimana tujuan penelitian ini adalah bagaimana menurunkan keterlambatan dalam pengiriman yang disebabkan proses produksi sehingga perlu adanya penjadwalan dalam proses produksi nya agar dapat berjalan lancar.

\section{METODE}

\section{Penjadwalan produksi}

Penjadwalan produksi (production scheduling) adalah pengalokasian sumber daya pada waktu tertentu dengan mengamati kapasitas sumber daya yang ada serta suatu proses dalam melakukan perencanaan dan pengendalian produksi yang merencanakan proses produksi (Subroto et al., 2019).

\section{Aturan prioritas}

Aturan prioritas ini digunakan untuk meminimasi waktu penyelesaian yang ada, jumlah pekerjaan dalam sistem, dan keterlambatan kerja melalui penggunaan mesin yang optimal. Dimana aturan prioritas memperhatikan deretan pekerjaan serta proses pelaksanaanya dengan satu mesin dalam melakukan proses produksi (Mulya et al., 2020).

Terdapat aturan yang perlu untuk diprioritaskan terlebih dahulu, dengan urutan pekerjaan atau job sequencing yaitu sebagai berikut.

1. Metode First Come First Served (FCFS) adalah sesuatu yang akan diproses terlebih dahulu ketika pesanan datang paling awal (Ervil \& Nurmayuni, 2018).

2. Metode Shortest Processing Time (SPT) merupakan suatu pekerjaan yang memiliki waktu pengerjaan lebih singkat sehingga akan diprioritaskan terlebih dahulu (Patricia \& Suryono, 2015).

3. Metode Longest Processing Time (LPT) yaitu pekerjaan yang akan dikerjakan terlebih dahulu apabila suatu perkejaan tersebut memiliki waktu proses terpanjang dan berlanjut untuk pekerjaan proses terpanjang kedua (Muharni et al., 2019).

4. Metode Earliest Due Date (EDD) yaitu pekerjaan yang harus dikerjakan terlebih dahulu yang memiliki penyelesaian paling awal (Patricia \& Suryono, 2015).

\section{Sumber data}

Dalam penelitian ini data yang digunakan yaitu data primer dan sekunder. Data primer dapat didefinisikan metode penelitian yang dilakukan secara langsung untuk memperoleh datanya. Sedangkan data sekunder yaitu dalam memperoleh data berasal dari data pendukung lainnya seperti dokumen perusahaan dan buku (Onibala et al., 2017). Dimana pada penelitian menggunakan data yang berasal dari jumlah pesanan komponen dari konsumen 3 bulan terakhir.

\section{Objek penelitian dan tempat penelitian}

Objek yang di lakukan dalam penelitian ini yaitu proses penjadwalan produksi yang optimal untuk meminimasi keterlambatan pengiriman. Penelitian ini dilakukan pada perusahaan yaitu PT. NSI yang bergerak dibidang jasa.

\section{Teknik pengumpulan data}

Dalam Teknik pengumpulan data yang dilakukan yaitu wawancara, dokumentasi dan observasi. 


\section{Pengolahan data}

Setelah data pesanan pelanggan diperoleh selanjunya melakukan pengolahan data dengan menerapkan metode First Come First Served (FCFS), Shortest Processing Time (SPT), Longest Processing Time (LPT), dan Earliest Due Date (EDD) yang nantinya akan dilihat dan dibandingkan metode mana yang paling optimal untuk digunakan dalam proses produksi.

\section{HASIL DAN PEMBAHASAN}

PT. NSI menerima pesanan dari konsumen yang sudah ditentukan due date nya sehingga perusahaan perlu melakukan proses produksi dengan tepat waktu. Dimana perusahaan memproduksi berbagai jenis komponen.

Tabel 2. Data permintaan

\begin{tabular}{cccccc}
\hline $\begin{array}{c}\text { Jumlah } \\
(\text { Item })\end{array}$ & $\begin{array}{c}\text { Tanggal } \\
\text { Pemesanan }\end{array}$ & Due Date & $\begin{array}{c}\text { Jumlah } \\
(\text { Item })\end{array}$ & $\begin{array}{c}\text { Tanggal } \\
\text { Pemesanan }\end{array}$ & Due Date \\
\hline 7 & 02-Dec-20 & 14-Dec-20 & 2 & 28-Jan-21 & 15-Jul-21 \\
1 & 02-Dec-20 & 17-Dec-20 & 5 & 25-Jan-21 & 02-Feb-21 \\
2 & 02-Dec-20 & 18-Dec-20 & 2 & 02-Feb-21 & 15-Aug-21 \\
2 & 08-Dec-20 & 18-Dec-20 & 2 & 02-Feb-21 & 25-Jun-21 \\
1 & 08-Dec-20 & 10-Dec-20 & 2 & 02-Feb-21 & 20-Jul-21 \\
3 & 08-Dec-20 & 01-Apr-21 & 1 & 02-Feb-21 & 15-Feb-21 \\
2 & 08-Jan-21 & 14-Jan-21 & 1 & 04-Feb-21 & 10-Feb-21 \\
2 & 15-Jan-21 & 20-Jan-21 & 1 & 05-Feb-21 & 23-Feb-21 \\
1 & 22-Jan-21 & 15-Feb-21 & 1 & 05-Feb-21 & 25-Feb-21 \\
1 & 22-Jan-21 & 08-Feb-21 & 2 & 03-Feb-21 & 25-Feb-21 \\
4 & 20-Jan-21 & 22-Jan-21 & 7 & 03-Feb-21 & 10-Mar-21 \\
1 & 27-Jan-21 & 15-Jul-21 & 2 & 11-Feb-21 & 08-Mar-21 \\
3 & 27-Jan-21 & 20-Jun-21 & 2 & 16-Feb-21 & 22-Feb-21 \\
3 & 27-Jan-21 & 15-Feb-21 & & & \\
\hline
\end{tabular}

Tabel 4 merupakan ringkasan dari data permintaan purchase order selama 3 bulan terakhir yaitu bulan Desember 2020 Januari 2021 dan Februari 2021. Adanya komponen yang dipesan tidak dapat diselesaikan dengan tepat waktu karena proses produksi yang tidak berjalan lancar atau dapat dikatakan tidak sesuai dengan tempo yang sudah ditetapkan sehingga dapat menyebabkan keterlambatan proses pengiriman. Maka perlu adanya penjadwalan dalam proses produksi dimana dengan menerapkan metode sequencing dengan aturan prioritas yaitu FCFS, SPT, LPT, dan EDD.

Menurunkan keterlambatan pesanan, mengoptimalkan jumlah pekerjaan, serta memperkecil proses pengerjaan yang dilakukan agar tugas dapat diselesaikan dengan cepat merupakan tujuan dari penggunaan metode pengurutan (Camelia, 2016). Berikut merupakan hasil perhitungannya.

\section{Metode first come first served (FCFS)}

Setalah data diurutkan seperti tabel 17 dengan metode FCFS salah satunya pada bulan Desember, maka selanjutnya hasil perhitungan berdasarkan aturan prioritas pada bulan Desember yaitu:

1. Waktu penyelesaian rata-rata

$$
=\frac{\sum \text { waktu aliran total }}{\sum \text { pekerjaan }}=\frac{1641}{16}=103 \text { Hari }
$$


2. Utilitas

$=\frac{\sum \text { waktu proses total }}{\sum \text { aliran waktu total }}=\frac{159}{1641}=10 \%$

3. Jumlah pekerjaan rata-rata

$=\frac{\sum \text { aliran waktu total }}{\sum \text { waktu proses total }}=\frac{1641}{159}=10,32 \mathrm{job}$

4. Keterlambatan pekerjaan rata-rata

$=\frac{\sum \text { hari keterlambatan }}{\sum \text { pekerjaan }}=\frac{1150}{16}=71,9$ hari

Untuk tabel berikut ini merupakan hasil dari perhitungan yang telah dilakukan berdasarkan metode FCFS yang ditunjukkan pada tabel 3 dan tabel 4.

Tabel 3. Hasil perhitungan FCFS bulan januari

\begin{tabular}{clc}
\hline No & \multicolumn{1}{c}{ Deskripsi } & Hasil \\
\hline 1 & Waktu Penyelesaian Rata-Rata (hari) & 81 \\
2 & Jumlah Pekerjaan Rata-Rata (pekerjaan) & 11,77 \\
3 & Keterlambatan Rata-Rata (hari) & 50,6 \\
4 & Utilitas $(\%)$ & $8 \%$ \\
\hline
\end{tabular}

Tabel 4. Hasil perhitungan FCFS bulan februari

\begin{tabular}{clc}
\hline No & \multicolumn{1}{c}{ Deskripsi } & Hasil \\
\hline 1 & Waktu Penyelesaian Rata-Rata (hari) & 108 \\
2 & Jumlah Pekerjaan Rata-Rata (pekerjaan) & 12,44 \\
3 & Keterlambatan Rata-Rata (hari) & 81,3 \\
4 & Utilitas $(\%)$ & $8 \%$ \\
\hline
\end{tabular}

Berdasarkan metode FCFS diperoleh waktu penyelesaian 103 hari, jumlah pekerjaan rata-rata 10,32 job, keterlambatan rata-rata 71,9 hari dengan utilitas $10 \%$ untuk bulan Desember, untuk bulan Januari diperoleh waktu penyelesaian rata-rata yaitu 81 hari, jumlah pekerjaan rata-rata 11,77 job, keterlambatan rata-rata 50,6 hari dengan utilitas $8 \%$, serta pada bulan Februari waktu penyelesaian yang diperoleh yaitu 108 hari, jumlah pekerjaan rata-rata 12,44 job, keterlambatan rata-rata 81,3 hari, dengan utilitas $8 \%$.

\section{Metode shortest processing time (SPT)}

Tabel berikut ini menunjukkan hasil perhitungan dengan metode SPT selama 3 bulan terakhir yang ditunjukkan pada tabel 5, tabel 6, dan tabel 7 .

Tabel 5. Hasil perhitungan SPT bulan desember

\begin{tabular}{clc}
\hline No & \multicolumn{1}{c}{ Deskripsi } & Hasil \\
\hline 1 & Waktu Penyelesaian Rata-Rata (hari) & 52 \\
2 & Jumlah Pekerjaan Rata-Rata (pekerjaan) & 5,26 \\
3 & Keterlambatan Rata-Rata (hari) & 39,2 \\
4 & Utilitas (\%) & $19 \%$ \\
\hline
\end{tabular}

Tabel 6. Hasil perhitungan SPT bulan Januari

\begin{tabular}{clc}
\hline No & \multicolumn{1}{c}{ Deskripsi } & Hasil \\
\hline 1 & Waktu Penyelesaian Rata-Rata (hari) & 59 \\
2 & Jumlah Pekerjaan Rata-Rata (pekerjaan) & 8,52 \\
3 & Keterlambatan Rata-Rata (hari) & 47,5 \\
4 & Utilitas (\%) & $12 \%$ \\
\hline
\end{tabular}


Tabel 7. Hasil perhitungan SPT bulan Februari

\begin{tabular}{clc}
\hline No & \multicolumn{1}{c}{ Deskripsi } & Hasil \\
\hline 1 & Waktu Penyelesaian Rata-Rata (hari) & 84 \\
2 & Jumlah Pekerjaan Rata-Rata (pekerjaan) & 9,62 \\
3 & Keterlambatan Rata-Rata (hari) & 42,6 \\
4 & Utilitas (\%) & $10 \%$ \\
\hline
\end{tabular}

Berdasarkan metode SPT diperoleh waktu penyelesaian 52 hari, jumlah pekerjaan ratarata 5,26 job, keterlambatan rata-rata 39,2 hari dengan utilitas 19\% untuk bulan Desember, untuk bulan Januari diperoleh waktu penyelesaian rata-rata yaitu 59 hari, jumlah pekerjaan rata-rata 8,52 job, keterlambatan rata-rata 47,5 hari dengan utilitas $12 \%$, serta pada bulan Februari waktu penyelesaian yang diperoleh yaitu 84 hari , jumlah pekerjaan rata-rata 9,62 $j o b$, keterlambatan rata-rata 42,6 hari, dengan utilitas $10 \%$.

\section{Metode longest processing time (LPT)}

Tabel berikut ini menunjukkan hasil perhitungan dengan metode LPT selama 3 bulan terakhir yang ditunjukkan pada tabel 8, tabel 9, dan tabel 10 .

\section{Tabel 8. Hasil perhitungan LPT bulan desember}

\begin{tabular}{clc}
\hline No & \multicolumn{1}{c}{ Deskripsi } & Hasil \\
\hline 1 & Waktu Penyelesaian Rata-Rata (hari) & 117 \\
2 & Jumlah Pekerjaan Rata-Rata (pekerjaan) & 11,74 \\
3 & Keterlambatan Rata-Rata (hari) & 85,8 \\
4 & Utilitas (\%) & $9 \%$ \\
\hline
\end{tabular}

Tabel 9. Hasil perhitungan LPT bulan januari

\begin{tabular}{clc}
\hline No & \multicolumn{1}{c}{ Deskripsi } & Hasil \\
\hline 1 & Waktu Penyelesaian Rata-Rata (hari) & 114 \\
2 & Jumlah Pekerjaan Rata-Rata (pekerjaan) & 16,48 \\
3 & Keterlambatan Rata-Rata (hari) & 71,0 \\
4 & Utilitas (\%) & $6 \%$ \\
\hline
\end{tabular}

Tabel 10. Hasil perhitungan LPT bulan februari

\begin{tabular}{clc}
\hline No & \multicolumn{1}{c}{ Deskripsi } & Hasil \\
\hline 1 & Waktu Penyelesaian Rata-Rata (hari) & 125 \\
2 & Jumlah Pekerjaan Rata-Rata (pekerjaan) & 14,38 \\
3 & Keterlambatan Rata-Rata (hari) & 81,8 \\
4 & Utilitas (\%) & $7 \%$ \\
\hline
\end{tabular}

Berdasarkan metode LPT diperoleh waktu penyelesaian 117 hari, jumlah pekerjaan rata-rata 11,74 job, keterlambatan rata-rata 85,8 hari dengan utilitas 9\% untuk bulan Desember, untuk bulan Januari diperoleh waktu penyelesaian rata-rata yaitu 114 hari, jumlah pekerjaan rata-rata 16,48 job, keterlambatan rata-rata 71 hari dengan utilitas $6 \%$, serta pada bulan Februari waktu penyelesaian yang diperoleh yaitu 125 hari , jumlah pekerjaan rata-rata 14,38 job, keterlambatan rata-rata 81,8 hari, dengan utilitas $7 \%$. 
Metode earliest due date (EDD)

Tabel berikut ini menunjukkan hasil perhitungan dengan metode EDD selama 3 bulan terakhir yang ditunjukkan pada tabel 11, tabel 12, dan tabel 13.

Tabel 11. Hasil perhitungan EDD bulan desember

\begin{tabular}{clc}
\hline No & \multicolumn{1}{c}{ Deskripsi } & Hasil \\
\hline 1 & Waktu Penyelesaian Rata-Rata (hari) & 83 \\
2 & Jumlah Pekerjaan Rata-Rata (pekerjaan) & 8,40 \\
3 & Keterlambatan Rata-Rata (hari) & 52,9 \\
4 & Utilitas (\%) & $12 \%$ \\
\hline
\end{tabular}

Tabel 12. Hasil perhitungan EDD bulan januari

\begin{tabular}{clc}
\hline No & \multicolumn{1}{c}{ Deskripsi } & Hasil \\
\hline 1 & Waktu Penyelesaian Rata-Rata (hari) & 92 \\
2 & Jumlah Pekerjaan Rata-Rata (pekerjaan) & 13,23 \\
3 & Keterlambatan Rata-Rata (hari) & 46,3 \\
4 & Utilitas (\%) & $8 \%$ \\
\hline
\end{tabular}

Tabel 13. Hasil perhitungan EDD bulan februari

\begin{tabular}{clc}
\hline No & \multicolumn{1}{c}{ Deskripsi } & Hasil \\
\hline 1 & Waktu Penyelesaian Rata-Rata (hari) & 95 \\
2 & Jumlah Pekerjaan Rata-Rata (pekerjaan) & 10,95 \\
3 & Keterlambatan Rata-Rata (hari) & 33,8 \\
4 & Utilitas (\%) & $9 \%$ \\
\hline
\end{tabular}

Berdasarkan metode EDD diperoleh waktu penyelesaian 83 hari, jumlah pekerjaan ratarata 8,40 job, keterlambatan rata-rata 52,9 hari dengan utilitas $12 \%$ untuk bulan Desember, untuk bulan Januari diperoleh waktu penyelesaian rata-rata yaitu 92 hari, jumlah pekerjaan rata-rata 13,23 job, keterlambatan rata-rata 46,3 hari dengan utilitas $8 \%$, serta pada bulan Februari waktu penyelesaian yang diperoleh yaitu 95 hari, jumlah pekerjaan rata-rata 10,95 job, keterlambatan rata-rata 33,8 hari, dengan utilitas $9 \%$.

Pada tabel berikut ini merupakan ringkasan dari hasil perhitungan yang telah dilakukan berdasarkan metode FCFS, SPT, LPT dan EDD pada bulan Desember, Januari dan Februari. Selanjutnya membandingkan hasil pengukuran efektivitas dari metode yang digunakan tersebut untuk mendapatkan metode yang optimal.

Tabel 14. Ringkasan perhitungan bulan desember 2020

\begin{tabular}{ccccc}
\hline Metode & $\begin{array}{c}\text { Waktu Penyelesaian Rata- } \\
\text { Rata (hari) }\end{array}$ & $\begin{array}{c}\text { Utilitas } \\
(\%)\end{array}$ & $\begin{array}{c}\text { Jumlah Pekerjaan Rata- } \\
\text { Rata (pekerjaan) }\end{array}$ & $\begin{array}{c}\text { Keterlambatan } \\
\text { Rata-Rata (hari) }\end{array}$ \\
\hline FCFS & 103 & $10 \%$ & 10,32 & 71,9 \\
SPT & 52 & $19 \%$ & 5,26 & 39,2 \\
LPT & 117 & $9 \%$ & 11,74 & 85,8 \\
EDD & 83 & $12 \%$ & 8,40 & 52,9 \\
\hline
\end{tabular}


Tabel 15. Ringkasan perhitungan bulan januari 2021

\begin{tabular}{ccccc}
\hline Metode & $\begin{array}{c}\text { Waktu Penyelesaian } \\
\text { Rata-Rata (hari) }\end{array}$ & $\begin{array}{c}\text { Utilitas } \\
(\%)\end{array}$ & $\begin{array}{c}\text { Jumlah Pekerjaan Rata- } \\
\text { Rata (pekerjaan) }\end{array}$ & $\begin{array}{c}\text { Keterlambatan Rata- } \\
\text { Rata (hari) }\end{array}$ \\
\hline FCFS & 81 & $8 \%$ & 11,77 & 50,6 \\
SPT & 59 & $12 \%$ & 8,52 & 47,5 \\
LPT & 114 & $6 \%$ & 16,48 & 71,0 \\
EDD & 92 & $8 \%$ & 13,23 & 46,3 \\
\hline
\end{tabular}

Tabel 16. Ringkasan perhitungan bulan februari 2021

\begin{tabular}{ccccc}
\hline Metode & $\begin{array}{c}\text { Waktu Penyelesaian } \\
\text { Rata-Rata (hari) }\end{array}$ & $\begin{array}{c}\text { Utilitas } \\
(\%)\end{array}$ & $\begin{array}{c}\text { Jumlah Pekerjaan Rata- } \\
\text { Rata (pekerjaan) }\end{array}$ & $\begin{array}{c}\text { Keterlambatan Rata- } \\
\text { Rata (hari) }\end{array}$ \\
\hline FCFS & 108 & $8 \%$ & 12,44 & 81,3 \\
SPT & 84 & $10 \%$ & 9,62 & 42,6 \\
LPT & 125 & $7 \%$ & 14,38 & 81,8 \\
EDD & 95 & $9 \%$ & 10,95 & 33,8 \\
\hline
\end{tabular}

Untuk tabel 17 sampai tabel 20 merupakan hasil pengurutan yang digunakan berdasarkan masing-masing metode dengan mengambil salah satu hasil pada bulan Desember untuk metode FCFS, bulan Januari untuk metode SPT, bulan Februari untuk metode LPT dan EDD. Dimana dari data yang diperoleh salama 3 bulan terakhir.

Tabel 17. Hasil pengurutan metode FCFS bulan desember

\begin{tabular}{|c|c|c|c|c|c|c|}
\hline No & Item & Qty & $\begin{array}{c}\text { Waktu } \\
\text { Proses } \\
\text { (Hari) }\end{array}$ & $\begin{array}{l}\text { Aliran } \\
\text { Waktu }\end{array}$ & $\begin{array}{l}\text { Due } \\
\text { Date }\end{array}$ & $\begin{array}{l}\text { Keterlambatan } \\
\quad \text { (hari) }\end{array}$ \\
\hline 1 & Stud - Include Material & 2 & 8 & 8 & 12 & 0 \\
\hline 2 & Cond-Finish Mach (Exclude) & 9 & 9 & 17 & 12 & 5 \\
\hline 3 & $\begin{array}{l}\text { Elerd - Finish Mach } \\
\text { (Exclude) }\end{array}$ & 2 & 9 & 26 & 12 & 14 \\
\hline 4 & Rod - Finish Mach (Exclude) & 3 & 22 & 48 & 12 & 36 \\
\hline 5 & B - Finish Mach (Exclude) & 12 & 23 & 71 & 12 & 59 \\
\hline 6 & $\begin{array}{l}\text { Cond - Finish Mach } \\
\text { (Exclude) }\end{array}$ & 3 & 23 & 94 & 12 & 82 \\
\hline 7 & Cond-Finish Mach (Exclude) & 1 & 23 & 117 & 12 & 105 \\
\hline 8 & $\begin{array}{l}\text { Elerd - Finish Mach } \\
\text { (Exclude) }\end{array}$ & 2 & 9 & 126 & 15 & 111 \\
\hline 9 & Shld - Finish Mach & 12 & 4 & 130 & 16 & 114 \\
\hline 10 & Plg-Finish Mach Exclude & 3 & 2 & 132 & 16 & 116 \\
\hline 11 & Cvr - Finish Part (Exclude) & 6 & 2 & 134 & 10 & 124 \\
\hline 12 & Cvr - Finish Mach & 6 & 4 & 138 & 10 & 128 \\
\hline 13 & Supp - Cutting & 1 & 3 & 141 & 2 & 139 \\
\hline 14 & Plt-Include Material & 12 & 6 & 147 & 114 & 33 \\
\hline 15 & Stud - Include Material & 6 & 6 & 153 & 114 & 39 \\
\hline 16 & Stud-Include Material & 6 & 6 & 159 & 114 & 45 \\
\hline \multicolumn{3}{|c|}{ Total } & 159 & 1641 & 495 & 1150 \\
\hline
\end{tabular}

Tabel 18. Hasil pengurutan metode SPT bulan januari

\begin{tabular}{clccccc}
\hline No & \multicolumn{1}{c}{ Order } & Qty & $\begin{array}{c}\text { Waktu } \\
\text { Proses } \\
\text { (Hari) }\end{array}$ & $\begin{array}{c}\text { Aliran } \\
\text { Waktu }\end{array}$ & $\begin{array}{c}\text { Due Date } \\
\text { (Hari) }\end{array}$ & $\begin{array}{c}\text { Keterlambatan } \\
\text { (hari) }\end{array}$ \\
\hline 6 & Plg-Finish Mach Exclude & 12 & 1 & 1 & 17 & 0 \\
1 & Seat - Finish Mach & 4 & 2 & 3 & 6 & 0 \\
3 & C1020p-1/2h - Cutting & 3 & 4 & 7 & 5 & 2 \\
& Disp - Include Material & & & & & 0 \\
11 & (Without Treatment) & 6 & 4 & 11 & 169 & 0 \\
\hline
\end{tabular}




\begin{tabular}{|c|c|c|c|c|c|c|}
\hline No & Order & Qty & $\begin{array}{c}\text { Waktu } \\
\text { Proses } \\
\text { (Hari) }\end{array}$ & $\begin{array}{l}\text { Aliran } \\
\text { Waktu }\end{array}$ & $\begin{array}{l}\text { Due Date } \\
\text { (Hari) }\end{array}$ & $\begin{array}{l}\text { Keterlambatan } \\
\text { (hari) }\end{array}$ \\
\hline 12 & $\begin{array}{l}\text { Disp - Include Material } \\
\text { (Without Treatment) }\end{array}$ & 6 & 4 & 15 & 144 & 0 \\
\hline 13 & $\begin{array}{l}\text { Disp - Include Material } \\
\text { (Without Treatment) }\end{array}$ & 6 & 4 & 19 & 144 & 0 \\
\hline 14 & $\begin{array}{l}\text { Disp - Include Material } \\
\text { (Without Treatment) }\end{array}$ & 6 & 4 & 23 & 144 & 0 \\
\hline 18 & $\begin{array}{l}\text { Disp - Include Material } \\
\text { (Without Treatment) }\end{array}$ & 6 & 4 & 27 & 168 & 0 \\
\hline 19 & $\begin{array}{l}\text { Disp - Include Material } \\
\text { (Without Treatment) }\end{array}$ & 6 & 4 & 31 & 168 & 0 \\
\hline 20 & Supp-Finish Mach & 4 & 4 & 35 & 8 & 27 \\
\hline 21 & Supp-Finish Mach & 3 & 4 & 39 & 8 & 31 \\
\hline 22 & Rod-Finish Mach & 1 & 5 & 44 & 8 & 36 \\
\hline 23 & Cond - Finish Mach & 1 & 5 & 49 & 8 & 41 \\
\hline 7 & $\begin{array}{l}\text { Cond - Finish Mach } \\
\text { Supp - Finish Mach - Exclude }\end{array}$ & 2 & 6 & 55 & 2 & 53 \\
\hline 5 & Material & 4 & 7 & 62 & 24 & 38 \\
\hline 8 & $\begin{array}{l}\text { Cond - Finish Mach } \\
\text { Bond - Milling As Per Finish }\end{array}$ & 5 & 7 & 69 & 2 & 67 \\
\hline 15 & Length & 3 & 7 & 76 & 19 & 57 \\
\hline 4 & C1020p-1/2h - Cutting & 8 & 8 & 84 & 5 & 79 \\
\hline 2 & Seat - Finish Mach & 24 & 10 & 94 & 6 & 88 \\
\hline 9 & Cond - Finish Mach & 5 & 11 & 105 & 2 & 103 \\
\hline 10 & Cond - Finish Mach & 6 & 13 & 118 & 2 & 116 \\
\hline 16 & Cond - Finish Mach (Exclude) & 3 & 14 & 132 & 19 & 113 \\
\hline 17 & Cond - Finish Mach (Exclude) & 3 & 17 & 149 & 19 & 130 \\
\hline 24 & Rod - Finish Mach & 1 & 17 & 166 & 8 & 158 \\
\hline \multicolumn{3}{|c|}{ Total } & 166 & 1414 & 1105 & 1139 \\
\hline
\end{tabular}

Tabel 19. Hasil pengurutan metode LPT bulan februari

\begin{tabular}{|c|c|c|c|c|c|c|}
\hline No & Order & Qty & $\begin{array}{c}\text { Waktu } \\
\text { Proses (Hari) }\end{array}$ & $\begin{array}{l}\text { Aliran } \\
\text { Waktu }\end{array}$ & $\begin{array}{l}\text { Due Date } \\
\text { (Hari) }\end{array}$ & $\begin{array}{l}\text { Keterlambatan } \\
\text { (hari) }\end{array}$ \\
\hline 10 & $\begin{array}{l}\text { Cyl/W - Milling Inside To } \\
\text { 19mm }\end{array}$ & 3 & 14 & 14 & 20 & 0 \\
\hline 19 & Bush - Finish Mach - Exclude & 24 & 14 & 28 & 35 & 0 \\
\hline 7 & Hook - Finish Part - Exclude & 6 & 13 & 41 & 13 & 28 \\
\hline 18 & Pin - Finish Mach - Exclude & 3 & 13 & 54 & 35 & 19 \\
\hline 17 & $\begin{array}{l}\text { Plt - Finish Mach - Exclude } \\
\text { Link - Include Material (Without }\end{array}$ & 6 & 11 & 65 & 35 & 30 \\
\hline 1 & $\begin{array}{l}\text { Material) } \\
\text { Link - Include Material (Without }\end{array}$ & 3 & 10 & 75 & 194 & 0 \\
\hline 2 & $\begin{array}{l}\text { Material) } \\
\text { Link - Include Material (Without }\end{array}$ & 3 & 10 & 85 & 143 & 0 \\
\hline 3 & $\begin{array}{l}\text { Material) } \\
\text { Link - Include Material (Without }\end{array}$ & 3 & 10 & 95 & 143 & 0 \\
\hline 4 & $\begin{array}{l}\text { Material) } \\
\text { Link - Include Material (Without }\end{array}$ & 3 & 10 & 105 & 194 & 0 \\
\hline 5 & Material) & 3 & 10 & 115 & 168 & 0 \\
\hline 6 & Link - Include Material (Without & 3 & 10 & 125 & 168 & 0 \\
\hline
\end{tabular}




\begin{tabular}{|c|c|c|c|c|c|c|}
\hline No & Order & Qty & $\begin{array}{c}\text { Waktu } \\
\text { Proses (Hari) }\end{array}$ & $\begin{array}{l}\text { Aliran } \\
\text { Waktu }\end{array}$ & $\begin{array}{l}\text { Due Date } \\
\text { (Hari) }\end{array}$ & $\begin{array}{l}\text { Keterlambatan } \\
\text { (hari) }\end{array}$ \\
\hline & \multicolumn{6}{|l|}{ Material) } \\
\hline 15 & B - Finish Mach - Exclude & 36 & 10 & 135 & 35 & 100 \\
\hline 16 & Fitg Finish Mach - Exclude & 12 & 9 & 144 & 35 & 109 \\
\hline 23 & $\begin{array}{l}\text { Bond - Cutting, Milling From } \\
\text { Thik } 12 \text { To Finish Drawing }\end{array}$ & 1 & 8 & 152 & 6 & 146 \\
\hline 9 & Cyl - Finish Mach & 3 & 7 & 159 & 18 & 141 \\
\hline 14 & Fitg - Finish Mach - Exclude & 12 & 7 & 166 & 35 & 131 \\
\hline 21 & Std.B - Finish Mach Exclude & 36 & 7 & 173 & 25 & 148 \\
\hline 13 & Pin - Finish Mach - Exclude & 9 & 6 & 179 & 35 & 144 \\
\hline 22 & $\begin{array}{l}\text { Bond - Cutting, Milling From } \\
\text { Thik } 12 \text { To Finish Drawing }\end{array}$ & 1 & 6 & 185 & 6 & 179 \\
\hline 8 & Seat-Finish Part - Exclude & 1 & 5 & 190 & 6 & 184 \\
\hline 20 & W - Finish Part Exclude & 24 & 4 & 194 & 25 & 169 \\
\hline 11 & Pin - Finish Mach - Exclude & 6 & 3 & 197 & 22 & 175 \\
\hline 12 & Pin - Finish Mach - Exclude & 6 & 3 & 200 & 22 & 178 \\
\hline \multicolumn{3}{|c|}{ Total } & 200 & 2876 & 1418 & 1881 \\
\hline
\end{tabular}

Tabel 20. Hasil pengurutan metode EDD bulan februari

\begin{tabular}{|c|c|c|c|c|c|c|}
\hline No & Order & Qty & $\begin{array}{l}\text { Waktu } \\
\text { Proses } \\
\text { (Hari) }\end{array}$ & $\begin{array}{l}\text { Aliran } \\
\text { Waktu }\end{array}$ & $\begin{array}{l}\text { Due } \\
\text { Date } \\
\text { (Hari) }\end{array}$ & $\begin{array}{l}\text { Keterlambatan } \\
\text { (hari) }\end{array}$ \\
\hline 8 & Seat-Finish Part - Exclude & 1 & 5 & 5 & 6 & 0 \\
\hline 22 & $\begin{array}{l}\text { Bond - Cutting, Milling From } \\
\text { Thik } 12 \text { To Finish Drawing }\end{array}$ & 1 & 6 & 11 & 6 & 5 \\
\hline & Bond - Cutting, Milling From & & & & & \\
\hline 23 & Thik 12 To Finish Drawing & 1 & 8 & 19 & 6 & 13 \\
\hline 7 & Hook - Finish Part - Exclude & 6 & 13 & 32 & 13 & 19 \\
\hline 9 & Cyl - Finish Mach & 3 & 7 & 39 & 18 & 21 \\
\hline 10 & Cyl/W - Milling Inside To 19mm & 3 & 14 & 53 & 20 & 33 \\
\hline 11 & Pin - Finish Mach - Exclude & 6 & 3 & 56 & 22 & 34 \\
\hline 12 & Pin - Finish Mach - Exclude & 6 & 3 & 59 & 22 & 37 \\
\hline 20 & W - Finish Part Exclude & 24 & 4 & 63 & 25 & 38 \\
\hline 21 & Std.B - Finish Mach Exclude & 36 & 7 & 70 & 25 & 45 \\
\hline 13 & Pin - Finish Mach - Exclude & 9 & 6 & 76 & 35 & 41 \\
\hline 14 & Fitg - Finish Mach - Exclude & 12 & 7 & 83 & 35 & 48 \\
\hline 15 & B - Finish Mach - Exclude & 36 & 10 & 93 & 35 & 58 \\
\hline 16 & Fitg Finish Mach - Exclude & 12 & 9 & 102 & 35 & 67 \\
\hline 17 & Plt - Finish Mach - Exclude & 6 & 11 & 113 & 35 & 78 \\
\hline 18 & Pin - Finish Mach - Exclude & 3 & 13 & 126 & 35 & 91 \\
\hline 19 & Bush - Finish Mach - Exclude & 24 & 14 & 140 & 35 & 105 \\
\hline 2 & $\begin{array}{l}\text { Link - Include Material (Without } \\
\text { Material) }\end{array}$ & 3 & 10 & 150 & 143 & 7 \\
\hline 3 & $\begin{array}{l}\text { Link - Include Material (Without } \\
\text { Material) }\end{array}$ & 3 & 10 & 160 & 143 & 17 \\
\hline 5 & $\begin{array}{l}\text { Link - Include Material (Without } \\
\text { Material) }\end{array}$ & 3 & 10 & 170 & 168 & 2 \\
\hline
\end{tabular}




\begin{tabular}{|c|c|c|c|c|c|c|}
\hline No & Order & Qty & $\begin{array}{l}\text { Waktu } \\
\text { Proses } \\
\text { (Hari) }\end{array}$ & $\begin{array}{l}\text { Aliran } \\
\text { Waktu }\end{array}$ & $\begin{array}{c}\text { Due } \\
\text { Date } \\
\text { (Hari) }\end{array}$ & $\begin{array}{l}\text { Keterlambatan } \\
\quad \text { (hari) }\end{array}$ \\
\hline 6 & $\begin{array}{l}\text { Link - Include Material (Without } \\
\text { Material) }\end{array}$ & 3 & 10 & 180 & 168 & 12 \\
\hline 1 & $\begin{array}{l}\text { Link - Include Material (Without } \\
\text { Material) }\end{array}$ & 3 & 10 & 190 & 194 & 0 \\
\hline 4 & $\begin{array}{l}\text { Link - Include Material (Without } \\
\text { Material) }\end{array}$ & 3 & 10 & 200 & 194 & 6 \\
\hline & Total & & 200 & 2190 & 1418 & 777 \\
\hline
\end{tabular}

Berdasarkan data yang diperoleh serta hasil perhitungan dengan menggunakan aturan prioritas yaitu metode FCFS (First Come First Served), SPT (Short Processing Time), LPT (Long Processing Time), dan EDD (Earliest Due Date) dengan waktu penyelesaian paling cepat, keterlambatan paling sedikit, jumlah pekerjaaan rata-rata sedikit dan memiliki nilai utilitas yang tinggi.

Sehingga diperoleh bahwa metode SPT (Short Processing Time) merupakan metode yang paling optimal dari metode pembanding lainnya yaitu dengan waktu penyelesaian ratarata 52 hari, nilai utilitas $19 \%$, jumlah pekerjaan rata-rata 5,26 job, keterlambatan rata-rata 39,2 hari pada bulan Desember. Waktu penyelesaian rata-rata 59 hari, nilai utilitas $12 \%$, jumlah pekerjaan rata-rata 8,52 job, keterlambatan rata-rata 47,5 hari pada bulan Januari. Selanjutnya pada bulan Februari waktu penyelesaian rata-rata 84 hari, nilai utilitas $10 \%$, jumlah pekerjaan rata-rata 9,62 job, keterlambatan rata-rata 42,6 hari.

\section{SIMPULAN}

Dari hasil analisis dan pengamatan yang telah dilakukan diperoleh bahwa metode SPT merupakan metode yang optimal. Adanya metode yang lebih optimal akan membantu perusahaan dalam proses produksi dengan tepat waktu sehingga dalam proses pengiriman kepada konsumen tidak akan mengalami keterlambatan kembali. Metode SPT (Short Processing Time) dapat diterapkan di perusahaan dengan sistem kerjanya yaitu pekerjaan yang memiliki waktu pengerjaan lebih singkat sehingga akan diprioritaskan terlebih dahulu. Selain itu, penambahan pada mesin dapat membantu dalam jalannya proses produksi agar berjalan dengan tepat waktu.

\section{DAFTAR PUSTAKA}

Camelia, A. F. (2016). Aplikasi Metode Sequencing Pada Jasa Service Kamera Digital Studi Kasus di MOR - C Photography Bandung. Jurnal Administrasi Bisnis, 12(2), 341838. https://doi.org/10.26593/jab.v12i2.2356.

Ervil, R., \& Nurmayuni, D. (2018). Penjadwalan Produksi Dengan Metode Campbell Dudek Smith (Cds) Untuk Meminimumkan Total Waktu Produksi (Makespan). Jurnal Sains Dan Teknologi: Jurnal Keilmuan Dan Aplikasi Teknologi Industri, 18(2), 97. https://doi.org/10.36275/stsp.v18i2.118

Febianti, E., \& Mardiana, A. (2019). Penjadwalan Produksi Single Machine Pada Pipa Longitudinal Welding Mesin Erw 2 Di Pt. Xyz. Journal Industrial Servicess, 5(1), 2329. https://doi.org/10.36055/jiss.v5i1.6495

Muharni, Y., Febianti, E., \& Sofa, N. N. (2019). Minimasi Makespan Pada Penjadwalan Flow Shop Mesin Paralel Produk Steel Bridge B-60 Menggunakan Metode Longest 
Processing Time Dan Particle Swarm Optimization. Journal Industrial Servicess, 4(2). https://doi.org/10.36055/jiss.v4i2.5154

Mulya, M. F., Trisanto, D., \& Rismawati, N. (2020). Analisis dan Implementasi Metode Earliest Due Date ( EDD) untuk Meminimalisir Keterlambatan dalam Proses Penjadwalan Perbaikan Kendaraan. 13(3), 168-175. https://doi.org/10.30998/faktorexacta.v13i3.7254

Onibala, A. G., Sondakh, M. L., Kaunang, R. . ., \& Mandei, J. . . (2017). Analisis FaktorFaktor Yang Mempengaruhi Produksi Padi Sawah Di Kelurahan Koya, Kecamatan $\begin{array}{llll}\text { Tondano Selatan. } & \text { Agri-Sosioekonomi, } & \text { 13(2A), }\end{array}$ https://doi.org/10.35791/agrsosek.13.2a.2017.17015

Patricia, E., \& Suryono, H. (2015). Analisis Penjadwalan Kegiatan Produksi Pada Pt . Muliaglass Float Division Dengan Metode Forward Dan Backward. 43(1), 71-79.

Subroto, W., Komputer, F. I., Buana, U. M., Herdi, T., Komputer, F. I., \& Buana, U. M. (2019). Sistem Pendukung Keputusan Dalam Menentukan Prioritas Penjadwalan Produksi Menggunakan Metode Edd ( Earliest Due Date) Dan Spt ( Shortest Processing Time ). 1(2), 39-48.

Supriyanto. (2013). OTIMASI WAKTU/PROSES PRODUKSI DI PT. SUMIDEN SINTERED COMPONENT INDONESIA DENGAN TEKNIK ANALISA NETWORK/PERT DAN METODE SMED. Journal of Chemical Information and Modeling, 53(9), 1689-1699.

Ulina, J., \& Bakhtiar, A. (2019). Analisis Faktor Penyebab Keterlambatan Produksi Dan Output Shortage Pada Pt Cedefindo. Industrial Engineering Online Journal. https://ejournal3.undip.ac.id/index.php/ieoj/article/view/23743 